RECYT

Year 23 / No 36 / 2021 / 14-23

\title{
Evaluation of phenotypic methods for the detection of carbapenemases applicable to low complexity laboratories
}

\section{Evaluación de métodos fenotípicos para la detección de carbapenemasas aplicables a laboratorios de poca complejidad}

\author{
Florencia A. Angelini ${ }^{1}{ }^{*}$, Eduardo R. Pegels ${ }^{1}$, Marina I. Quiroga ${ }^{1}$ \\ Faculty of Exact, Chemical and Natural Sciences. National University of Misiones. \\ *E-mail: flo.ang04@gmail.com
}

Received: 19/01/2021; Approved 13/05/2021

\section{Abstract}

\begin{abstract}
The spread of carbapenemase-producing gram-negative bacilli is a global public health problem. Several authors have proposed phenotypic assays to presumptively detect these enzymes applicable to low and medium complexity laboratories. In the present study, we have developed and compared different phenotypic techniques using strains genetically identified as carbapenemase-producing. All the tested methods detected the presence of carbapenemases. The carbapenem inactivation method (MIC) and the modified carbapenem inactivation method with and without EDTA (MMIC-eMIC) were the simplest and easiest to interpret but their disadvantage was on the time required to obtain results. The direct Carba NP and Carba-Blue colourimetric methods were the fastest but they depend on reagent preparation and accurate $\mathrm{pH}$ adjustment of the solutions. Synergy methods with EDTA discs, boronic acid and the Triton Hodge Test (THT) require technical expertise to evaluate true synergism. Whereas, the Disk Carbapenemase Test (DCT) was the method that presented the greatest technical difficulties.
\end{abstract}

Keywords: Word 1; Word 2; Word 3.

\section{Resumen}

La diseminación de bacilos gramnegativos productores carbapenemasas es un problema mundial de salud pública. Diversos autores han propuesto ensayos fenotípicos para detectar presuntivamente estas enzimas aplicables a laboratorios de baja y mediana complejidad.

En el presente trabajo, hemos puesto a punto y comparado diferentes técnicas fenotípicas utilizando cepas identificadas genéticamente como productoras de carbapenemasas.

Todos los métodos analizados detectaron la presencia de carbapenemasas.

El método de inactivación de carbapenemes (MIC) y el método de inactivación de carbapenemes modificado con y sin EDTA (mMIC-eMIC) fueron los más sencillos y de fácil interpretación pero presentan la desventaja del tiempo necesario para obtener resultados. Los métodos colorimétricos Carba NP directo y Carba-Blue resultaron los más rápidos pero dependen de la preparación de reactivos y de un exacto ajuste de pH de las soluciones. Los métodos de sinergia con discos de EDTA, ácido borónico y el Triton Hodge Test (THT), requieren experiencia técnica para evaluar verdadero sinergismo. Mientras, que el Disk Carbapenemase Test (DCT) fue el método que presentó mayores dificultades técnicas.

Palabras clave: Phenotypic methods; ß-lactamases; Serine-carbapenemases; Metallo ß-lactamases; Gram-negative bacilli; Gram-negative bacilli

Introduction

The spread of antibiotic resistant bacteria in both human and veterinary isolates is of particular concern in carbapenemase-producing gram-negative bacilli (1). These enzymes represent the most important mechanism of carbapenem resistance in gram-negative bacilli because of their frequency, their ability to spread when encoded by genes inserted in plasmids, transposons or integrons, and their epidemiological and clinical implications $(2,3)$.

Carbapenemase-producing strains are considered a problem mainly when associated with infections in critically ill patients since they have a high mortality rate in these conditions $(4,5,6)$. For this reason, it is 
essential to keep its prevalence at a low level and thus avoid its dissemination in hospital environment. The quick detection and confirmation of carrier patients is essential to implement early isolation protocols.

Carbapenemases are placed by their molecular structure in Ambler classes A, B and D (7), which correspond to functional groups $2 \mathrm{f}, 3$ and $2 \mathrm{df}$ in the 2010 Bush and Jacoby classification, respectively (8). Classes A and D correspond to enzymes containing serine in their active site and are called serine-carbapenemases, while class B is called metallo ß-lactamases (MBL) due to its dependence on zinc (3).

Class A enzymes are characterized by a phenotype with a marked loss of sensitivity to carbapenems and a hydrolytic profile that includes aztreonam and to a lesser extent third and fourth generation cephalosporins, are mildly inhibited by clavulanic acid and tazobactam and are not inhibited by EDTA (ethylenediaminetetraacetic acid). In this group, where the $\beta$-lactamases are found: SME (Serratia marcescens enzyme); enzymes related to the IMI (Imipenem hydrolyzing $\beta$-lactamase), NMC (Not metallo enzyme carbapenemase) groups and some variants of BLEE (extended spectrum $\beta$-lactamases) of the GES (Guiana extended spectrum $\beta$-lactamase) type $(3,9)$, the most epidemiologically important are the so-called KPC (Klebsiella pneumoniae carbapenemase) which efficiently hydrolyse penicillins, cephalosporins and carbapenems, and are not inhibited by clavulanic acid, but are inhibited by boronic acid (BOR) $(10,11)$. Group D comprises enzymes called OXA (Oxacillin hydrolyzing $\beta$-lactamase). OXA phenotypic detection is complex because, in many cases, hydrolysis of carbapenems is inefficient and virtually non-existent for the third and fourth generation cephalosporins, and they are poorly inhibited by clavulanic acid, sulbactam or tazobactam (12).

Finally, among the MBLs, there are several types such as IMP (Imipenemase), VIM (Verona integron encoded metallo- $\beta$-lactamase), SPM (Sao Paulo metallo- $\beta$ lactamase), NDM (New Delhi metallo- $\beta$-lactamase), among others, which hydrolyze all $\beta$-lactam antibiotics with the exception of aztreonam and are only inhibited by divalent cation chelating agents such as EDTA, thiol compounds such as 2-mercaptopropionic acid, or dipicolinic acid $(3,13)$.

Among the carbapenemases mentioned, the most effective in terms of their ability to hydrolyze carbapenems and disseminate are KPC (Class A), IMP, VIM, NDM (all MBL) and OXA-48 (Class D) $(14,15)$.

Although molecular techniques allow genes confirmation presence encoding the different carbapenemases, these techniques are often not available in the context of routine clinical practice. For this reason, several phenotypic assays have been proposed to presumptively detect the presence of carbapenemases in clinical isolates, which are relatively simple, inexpensive and applicable in low/medium complexity laboratories.
Among the most commonly used phenotypic assays, there are assays where carbapeneme containing discs are used against discs containing inhibitors (double disc assays) such as EDTA (to inhibit MBL) or BOR (to inhibit serine-carbapenemases) (16). Other rapid methods for the detection of carbapenemases based on changes in $\mathrm{pH}$ values produced when the $\beta$-lactam ring is hydrolysed have been published. The first to be described was the Carba NP (CNPt) developed by Nordmann et al. (17). Subsequently, the method was modified by Pasteran et al. (18), improving its sensitivity and making it more accessible to low/ medium complexity laboratories.

Another similar method is the Carba Blue method proposed by Pasteran et al. (19), which the authors refer to as $100 \%$ sensitive and specific for Enterobacteriaceae, Pseudomonas spp. and carbapenemase-producing Acinetobacter spp. In 2014, Van der Zwaluw et al.(20) developed a method called the Carbapenem Inactivation Method (MIC) for the detection of carbapenemase activity in gram-negative bacilli. The method, according to the authors, has the advantage of being inexpensive and easy to perform and is not affected by changes in variables such as temperature or incubation time. On the other hand, they argue that it minimizes the possibility of false positives from strains with reduced susceptibility to carbapenems by mechanisms other than the production of carbapenemase-type enzymes. Since 2018, the Clinical and Laboratory Standards Institute (CLSI) (21) have proposed a technique similar to MIC, called the Modified Carbapenem Inactivation Method for Carbapenems (mMIC). In addition, it recommends simultaneously performing another identical assay in parallel but with the addition of EDTA for the detection of MBL (EDTA modified carbapenem inactivation method, eMIC).

In 2016, Kim et al. (22) proposed a new disc test (DCT, Disk Carbapenemase Test) which, according to the authors, allows rapid detection of carbapenemase-producing gramnegative bacilli such as KPC, NDM, IMP, VIM, and SPM. In the same year Pasterán et al. (23) developed the Triton Hodge Test (THT) which is a modification of the Hodge method (MHT) suggested by CLSI (24). According to the authors, the use of Triton X-100 allows the release of the NDM enzyme from the bacterial membrane, increasing the sensitivity for the detection of NDM and other carbapenemases. In view of the clinical implications of these resistant micro-organisms, their rapid detection is essential to reduce their circulation in hospital environment. Therefore, it is necessary that microbiological diagnostic laboratories without access to molecular methods can rely on simple, rapid and inexpensive techniques to detect the presence of carbapenemases, not only to provide epidemiological data for their locality but also because the failure or success of antimicrobial therapy may depend on it. Therefore, in this work we have proposed to develop and evaluate different phenotypic methods applicable to low 
or medium complexity clinical laboratories to detect the production of carbapenemases in strains producing IMP, VIM, SPM, KPC and NDM enzymes in a simple, efficient and rapid way.

\section{Materials and Methods}

\section{Micro-organisms}

Strains genetically identified as carbapenemaseproducing at the Laboratory of Bacterial Resistance, Faculty of Pharmacy and Biochemistry, University of Buenos Aires were included in the study. The following strains were used: Pseudomonas aeruginosa (P. aeruginosa) producing IMP-type $\beta$-lactamase, P. aeruginosa producing SPM-type $\beta$-lactamase, P. aeruginosa producing VIM-type $\beta$-lactamase, Klebsiella pneumoniae (K pneumoniae) producing KPC-type serine-carbapenemase, Providencia rettgeri (P. rettgeri) producing NDM-type $\beta$-lactamase and, as negative controls, the non-carbapenemase producing strains: P. aeruginosa ATCC 27853 and Escherichia coli (E. coli) ATCC 25922, preserved in sterile water at $4{ }^{\circ} \mathrm{C}$ or $0.7 \%$ semi-solid agar (Pluripeptone $5 \mathrm{~g} / \mathrm{L}$, Meat extract $3 \mathrm{~g} / \mathrm{L}, \mathrm{NaCl} 8 \mathrm{~g} / \mathrm{L}$, Agar $7.5 \mathrm{~g} / \mathrm{L}$, distilled H2O, pH: 7) depending on the micro-organism involved. In order to have strains with 18-24 h development during the development of the proposed assays, MBL strains were recovered on Columbia agar to which zinc sulphate $(0.07$ $\mathrm{g} / \mathrm{L}$ ) was added to increase enzyme production, while KPCproducing strains and negative controls were recovered on Columbia agar without the addition of zinc sulphate.

\section{Synergy test with EDTA and BOR (boronic acid) discs}

The assays were performed according to the methodology described by Prat Miranda (25) with commercial IPM and meropenem (MEM) discs (10 $\mu \mathrm{g}$, Bio-Rad Laboratories, France). For the preparation of EDTA discs ( $1 \mu \mathrm{g}$ EDTA/disc), the methodology described in the document of the Subcommittee on Antimicrobials (SADEBAC-AAM) was used (26). For the development of the method, each strain to be studied was suspended in sterile distilled water, adjusting the inoculum until a turbidity equivalent to 0.5 on the McFarland scale (MF) was reached. Suspensions were seeded on $\mathrm{MH}$ agar plates according to the standard procedure of the disc diffusion method (27). For the KPC-producing strain, the BOR disc (300 $\mu \mathrm{g}$, Laboratorios Britania, Argentina) was placed in the center of the plate, and at a distance of $1.5 \mathrm{~cm}$ (edge to edge), an IPM disc and a MEM disc were placed on opposite sides. The same procedure, but replacing the BOR disc with an EDTA disc, was used for all MBL-producing strains. For negative controls, EDTA and BOR discs were placed on each plate, each $1.5 \mathrm{~cm}$ edge-to-edge apart from the carbapenem discs. Plates were incubated at $35{ }^{\circ} \mathrm{C}$ for $24 \mathrm{~h}$ in an aerobic atmosphere. The observation of an enlargement of the inhibition halo in the confluence zone of antibiotics and discs containing inhibitors, EDTA and/ or BOR was considered a positive result.

\section{Carba NP direct test (CNP-direct)}

The modification proposed by Pasteran et al. (18) was used and, in addition, it was tested without the addition of Triton X-100. For this purpose, two solutions were prepared, called solution A and solution B. Solution A was prepared by diluting $2 \mathrm{~mL}$ of $0.05 \%$ phenol red in $16.6 \mathrm{~mL}$ of distilled water (final concentration $0.5 \% \mathrm{w} / \mathrm{v}$ ). Then, $180 \mu \mathrm{L}$ of zinc sulphate solution $(10 \mathrm{mM})$ was added to achieve a concentration equivalent to $0.1 \mathrm{mM}$ and Triton $\mathrm{X}-100$ at a concentration of $0.1 \%(\mathrm{v} / \mathrm{v})$. The $\mathrm{pH}$ of the solution was adjusted to a value of 8 . From solution A, solution $\mathrm{B}$ was prepared by adding to $1 \mathrm{~mL}$ of solution A, $12 \mathrm{mg}$ of commercial imipenem/cilastatin (commercial IPM) to reach a final IPM concentration of $6 \mathrm{mg} / \mathrm{mL}$. For each strain to be tested, two wells of a 96-well polycuvette were used. In one well, $100 \mu \mathrm{L}$ of solution A (control well) was added, and in the second, $100 \mu \mathrm{L}$ of solution B (reaction well) was added. In each well, 5 to 8 colonies of the strain to be tested were inoculated with a wooden stick. The polycube was incubated at $37^{\circ} \mathrm{C}$ with shaking at $150 \mathrm{rpm}$. The observation was done visually, checking the colour changes every 15 minutes for a maximum time of 2 hs. The colour change of the well containing Solution $\mathrm{B}$ from red to orange/yellow was interpreted as a positive result. The colour change of the well containing Solution B from red to orange/yellow was interpreted as a positive result. In the modification carried out by our research group, we worked in the same way as described above, with the difference that Triton X-100 was not added when preparing the solutions.

\section{Carba-Blue Method}

We worked with the modification proposed by Pasteran et al. (19) of the CNP-direct test using bromothymol blue as an indicator. Observation was carried out visually, controlling the colour changes every 15 minutes for a maximum time of $2 \mathrm{hs}$. Results obtained after $2 \mathrm{hs}$ of incubation were considered for further analysis. A change in colour of the well containing the MPI solution from blue to green/yellow was interpreted as a positive result.

\section{Carbapenem Inactivation Method (MIC)}

The modification proposed by Van der Zwaluw et al. (20) was used, whereby 10 colonies of each of the strains under study were suspended in $400 \mu \mathrm{L}$ of sterile distilled water. Then, by using sterile forceps, a disc of MEM (10 $\mu \mathrm{g}$, Bio-Rad Laboratories, France) was placed in each tube. The tubes were incubated for $2 \mathrm{~h}$ at $35^{\circ} \mathrm{C}$ in aerobiosis and then the discs were removed with an eyelet loop and placed on an $\mathrm{MH}$ agar plate previously inoculated with a turbidity suspension equivalent to $0.5 \mathrm{MF}$ of the standard strain E. coli ATCC 25922, according to the standard 
procedure of the disc diffusion method (43). After the discs were placed, the plates were incubated at $35^{\circ} \mathrm{C}$ for $24 \mathrm{~h}$ in aerobiosis. The absence of inhibition halo around the discs indicated degradation of the antibiotic by the action of carbapenemases.

\section{Modified Carbapenem Inactivation Method (MMIC) and modified Carbapenem Inactivation Method + EDTA (eMIC)}

We worked with the methodology proposed by the CLSI (21), whose technique is identical to the one described in MIC except that it uses CTS instead of distilled water to make the bacterial suspensions and that the incubation time of the tubes is 4 hours. For MBL detection, the eMIC method was performed in parallel to the mMIC method. For this, $20 \mu \mathrm{l}$ of a $0.5 \mathrm{M}$ EDTA solution was placed in a tube with $2 \mathrm{~mL}$ of CTS to obtain a final EDTA concentration of $5 \mathrm{mM}$. These tubes were worked in the same way as previously described. The increase of the zone of inhibition by $\geq 5 \mathrm{~mm}$ of eMIC vs. mMIC was interpreted as a positive result for MBL.

\section{Disk Carbapenemase Test (DCT)}

The modification proposed by Kim et al. (22) was used. In an eppendorf conical microtube, $0.03 \mathrm{~g}$ of commercial IPM was weighed and $800 \mu 1 \mathrm{NaCl}(12 \mathrm{mg} / \mathrm{mL})$ and 100 $\mu \mathrm{ZnSO} 42 \mathrm{mM}$ were added. After complete dissolution of the antibiotic, $100 \mu \mathrm{l}$ of a $0.8 \%$ bromothymol blue solution (pH: 7) was added and $20 \mu \mathrm{l}$ of the solution was deposited on sterile filter paper discs (Whatmann No. 3) of $6 \mathrm{~mm}$ diameter. The discs were placed in an oven at $37^{\circ} \mathrm{C}$ for 1 $\mathrm{h}$. To determine the production of carbapenemases, one of the discs prepared according to the above description was placed on each strain under study and gently pressed with forceps. The disc was immediately lifted and placed in 20 $\mu \mathrm{L}$ of distilled water in a Petri dish with the impregnated side with the strain facing upwards. As a negative control, uninoculated disks soaked in distilled water were used. A change in disc colour from green to yellow was interpreted as a positive result. Visualisation was performed at room temperature every $5 \mathrm{~min}$ for $1 \mathrm{~h}$.

\section{Triton Hodge Test (THT)}

The method modified by Pasterán et al. (23) was used, using MEM discs (10 $\mu \mathrm{g}$, Bio-Rad Laboratories, France). For the preparation of the plates, $50 \mu 1$ of pure Triton $\mathrm{X}-100$ was placed in the centre of each $\mathrm{MH}$ agar plate and rapidly distributed with a swab over the entire surface until complete absorption. Subsequently, a $0.5 \mathrm{MF}$ standard suspension of E. coli strain ATCC 25922 (indicator strain) was prepared and seeded on the MH agar plate according to the standard procedure of the disc diffusion method (27). After drying the plate for 10 minutes at $35^{\circ} \mathrm{C}$, an MEM disc was placed in the centre of the plate and the strains under study were streaked from the disc in the centre to the periphery of the plate (without touching the disc).
The observation of an overgrowth of the indicator strain towards the carbapenem disc at the intersection of the streak with the zone of inhibition was considered a positive result. All the above tests were performed in duplicate.

\section{Comparison of techniques}

The techniques were compared according to their difficulty of set-up, ease of interpretation of results, ability to distinguish between MBL and serine-carbapenemases, and final time required for visualisation of results. The difficulty of fine-tuning was categorized as low, medium and high. Low difficulty was defined as those techniques that gave optimal results in the first instance and therefore did not need to be repeated, medium difficulty was defined as those techniques that necessarily had to be repeated twice and high difficulty was defined as those techniques that did not show satisfactory results in more than two attempts. In terms of result interpretation, techniques were categorized into easy and difficult. An easy assignment was given to those techniques that presented clear results, and showed agreement with what was reported by two or more test observers. While those whose results gave rise to disagreement between two or more observers were designated as difficult.

The ability to distinguish between MBL and serine carbapenemases was categorized as present or absent. The time for obtaining the results was defined as: minimum time at the time when all carbapenemase-producing strains were positive, and maximum time at the final incubation time indicated in the methodology by the different authors.

\section{Results}

In all tests performed, the carbapenemase-producing strains performed as expected (Table 1). 
Table 1: Results obtained in phenotypic assays for carbapenemases on serine- and metallo B-lactamase-producing strains.

\begin{tabular}{|c|c|c|c|c|c|c|c|c|}
\hline \multirow{2}{*}{\multicolumn{2}{|c|}{$\begin{array}{c}\text { Ensayos: } \\
\text { KPC }\end{array}$}} & \multicolumn{5}{|c|}{$\begin{array}{l}\text { Micro-organisms producing } \\
\text { carbapenemase type } \\
\text { carbapenemases: }\end{array}$} & \multicolumn{2}{|c|}{$\begin{array}{l}\text { Negative } \\
\text { controls }\end{array}$} \\
\hline & & VIM & \multirow{2}{*}{ IMP } & \multirow{2}{*}{\begin{tabular}{|c|} 
NDM \\
+ \\
\end{tabular}} & \multirow{2}{*}{$\begin{aligned} \text { SPM } \\
+ \\
\end{aligned}$} & \multirow{2}{*}{$\begin{array}{c}\text { E. coli } \\
\text { ATCC } \\
25922 \\
+\end{array}$} & \multirow{2}{*}{ 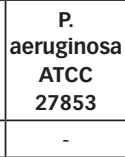 } & \multirow[b]{2}{*}{ - } \\
\hline \multirow{3}{*}{$\begin{array}{l}\text { Synergy } \\
\text { with EDTA } \\
\text { and BOR } \\
\text { discs }\end{array}$} & EDTA & - & & & & & & \\
\hline & BOR & + & - & - & - & - & - & - \\
\hline & Interpretation & No MBL & MBL & MBL & MBL & MBL & $\mathrm{NP}$ & NP \\
\hline \multicolumn{2}{|c|}{ CNPt-direct } & + & + & + & + & + & - & - \\
\hline \multicolumn{2}{|c|}{ Carba-Blue } & + & + & + & + & + & - & - \\
\hline \multicolumn{2}{|c|}{ MIC } & + & + & + & - & + & - & - \\
\hline \multirow{3}{*}{$\begin{array}{l}\text { Inhibition } \\
\text { halos } \\
\text { (mm) } \\
\text { of the } \\
\text { indicator } \\
\text { strain } \\
\text { against } \\
\text { MEM: }\end{array}$} & mMIC & 6 & 6 & 6 & 6 & 6 & 27 & 27 \\
\hline & eMIC & 6 & 29 & 28 & 28 & 27 & 25 & 25 \\
\hline & Interpretation & No MBL & MBL & MBL & MBL & MBL & NP & NP \\
\hline \multicolumn{2}{|r|}{ DCT } & + & + & + & + & + & - & - \\
\hline \multicolumn{2}{|c|}{ THT } & + & + & + & + & + & NR & - \\
\hline
\end{tabular}

KPC: KPC-type serine-carbapenemase-producing K. pneumoniae, VIM: VIM-type B-lactamaseproducing P. aeruginosa, IMP: IMP-type B-lactamase-producing P. aeruginosa, NDM: NDM-type B-lactamase-producing P. rettgeri, SPM: SPM-type B-lactamase-producing P. aeruginosa, SPM: SPM-type B-lactamase-producing P. aeruginosa. CNPt-direct: Carba NP direct test, MIC: Carbapenem Inactivation Method, mMIC: modified Carbapenem Inactivation Method, eMIC: modified Carbapenem Inactivation Method + EDTA, DCT: Disk Carbapenemase Test, THT: Triton Hodge Test. MEM: meropenem. EDTA: ethylenediaminetetraacetic acid, BOR: boronic acid, MBL: metallo B-lactamase, NP: non-carbapenemase producing, NR: not performed.

The KPC-producing strain showed synergy against BOR, while the MBL-producing strains (VIM, IMP, NDM, and SPM) showed synergy against EDTA (Figure 1).

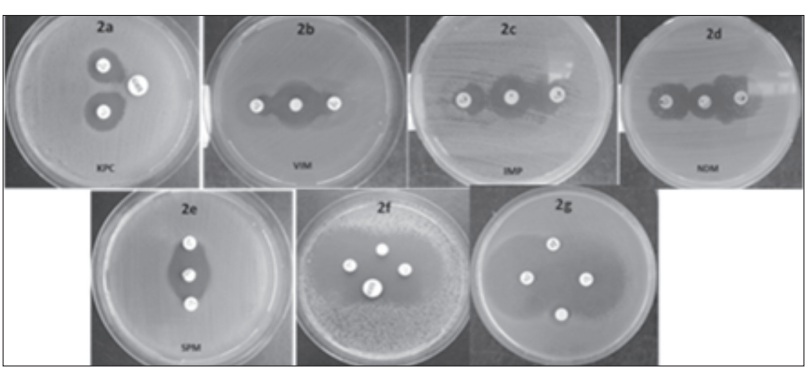

Figure 1: Synergy assay with imipenem and meropenem discs against EDTA and BOR (boronic acid). a: KPC-producing K. pneumoniae, b: VIM-producing P. aeruginosa, b:, c: VIM-producing P. aeruginosa, d: IMP-producing P. aeruginosa, e: NDM-producing P. rettgeri, e: SPMproducing P. aeruginosa, f: non-carbapenemase-producing E. coli ATCC 25922, g: non-carbapenemase-producing P. aeruginosa ATCC 27853.

In the Carba NP-direct method, carbapenemaseproducing strains showed a colour change to yellow in the reaction wells, indicating antibiotic cleavage (Figure 2). After 2 hours of incubation, identical results were obtained with the modification made by the research group (without the addition of Triton X-100). The observation of positive results was faster with the approach of Pasterán et al. (18), as the colour change was immediately after sowing, except for the VIM-producing strain which took 20 minutes to produce the indicator change. In the research group's modification, only the KPC- and SPM-producing strains gave positive results immediately after seeding, the remaining strains produced the indicator change within one hour of incubation.

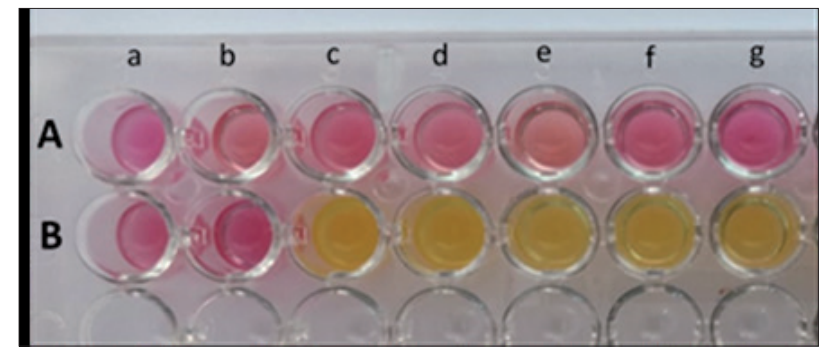

Figure 2: Carba NP-direct assay. A: Control wells, B: Reaction wells. a: non-carbapenemase-producing E. coli ATCC 25922, b: non-carbapenemase-producing P. aeruginosa ATCC 27853, c: KPC-producing K. pneumoniae, d: VIM-producing P. aeruginosa, e: IMP-producing P. aeruginosa, f: NDM-producing P. rettgeri, g: SPM-producing P. aeruginosa.

With the Carba-Blue method, after $2 \mathrm{~h}$ of incubation, all carbapenemase-producing strains tested positive (Figure 3). Only the KPC-producing strain gave a positive result immediately after seeding, the SPM-producing strain within 5 minutes and the rest within 30 minutes, except for the VIM-producing strain which took $1 \mathrm{~h}$ and 20 minutes to produce the indicator shift.

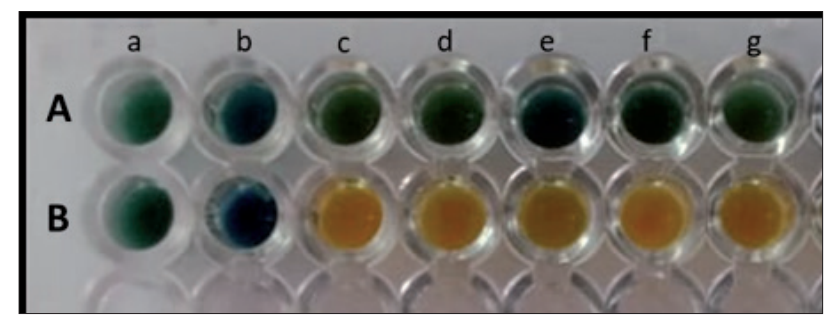

Figure 3: Carba Blue assay with imipenem as substrate. A: Control wells, B: Reaction wells. a: non-carbapenemase-producing E. coli ATCC 25922, b: non-carbapenemase-producing P. aeruginosa ATCC 27853, c: KPC-producing K. pneumoniae, d: SPM-producing P. aeruginosa, e: VIM-producing P. aeruginosa, f: IMP-producing P. aeruginosa, g: NDMproducing $P$. rettgeri.

When MIC was performed the NDM, VIM, SPM and $\mathrm{KPC}$ producing strains were able to degrade the antibiotic and therefore no inhibition halos were observed on the plate seeded with the E indicator strain. coli ATCC 25922. La cepa productora de IMP presentó un halo de inhibición de $16 \mathrm{~mm}$, y la presencia de colonias alrededor del disco, por lo que se consideró el resultado como negativo. (Figura 4) coli ATCC 25922. The IMP-producing strain showed an inhibition halo of $16 \mathrm{~mm}$, and the presence of colonies around the disc, so the result was considered negative. (Figure 4) 


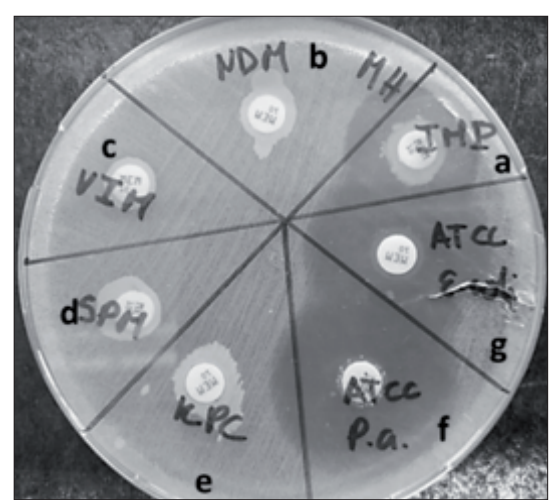

Figure 4: Carbapenem Inactivation Method (MIC). a: P. aeruginosa producing IMP. b: P. rettgeri producing NDM. c: VIM-producing P. aeruginosa. d: SPM-producing P. aeruginosa. e: KPC-producing K. pneumoniae. f: Non-carbapenemase-producing P. aeruginosa ATCC 27853. g: Non-carbapenemase-producing E. coli ATCC 25922.

In the mMIC / eMIC method, the serine-carbapenemase KPC did not show an increase in the inhibition halo against MEM when EDTA was added, indicating that EDTA did not influence carbapenemase activity. MBL IMP, VIM, NDM and SPM showed an increase in the zone of inhibition against MEM ( $\geq 5 \mathrm{~mm})$ when EDTA was added. (Figure 5).

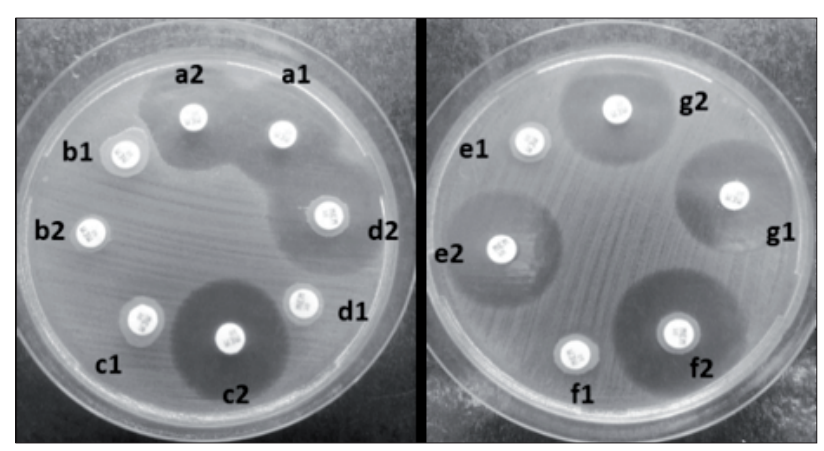

Figure 5: Modified Carbapenem Inactivation Method (mMIC) and modified Carbapenem Inactivation Method + EDTA (eMIC). eMIC. a1: mMIC non-carbapenemase-producing E. coli ATCC 25922, a2: eMIC carbapenemase-producing E. coli ATCC 25922 non-carbapenemase-producing, b1: MMIC K. pneumoniae KPC-producing, b2: eMIC K. pneumoniae KPC-producing, c1: mMIC P. rettgeri NDM-producing, c2: eMIC P. rettgeri NDM-producing, d1: mMIC P. aeruginosa SPM-producing, d2: eMIC P. aeruginosa SPM-producing, e1: mMIC P. aeruginosa IMP-producing, e2: eMIC P. aeruginosa IMP-producing, f1: mMIC P. aeruginosa VIM-producing, f2: eMIC P. aeruginosa VIM-producing, g1: mMIC P. aeruginosa ATCC 27853 non-carbapenemase-producing, g2: eMIC P. aeruginosa ATCC 27853 non-carbapenemase-producing, g2: eMIC P. aeruginosa ATCC 27853 non-carbapenemase-producing.

For DCT (Figure 6), the discs changed colour when inoculated with KPC, SPM, IMP and VIM producing strains immediately. NDM showed colour change after 15 min. Once the discs were dried (approx. $1 \mathrm{~h}$ ), disc disc disc discolouration was observed and the results could no longer be interpreted.

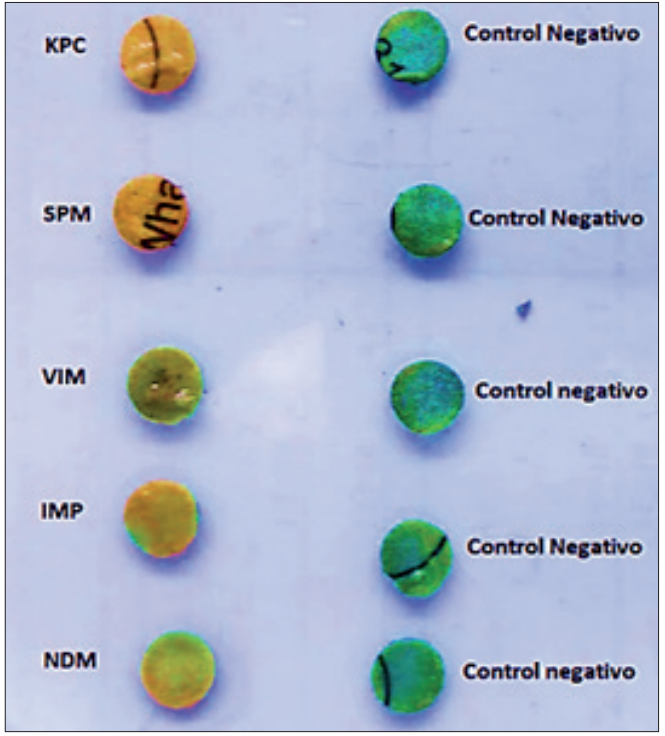

Figure 6: Disk Carbapenemase Test (DCT). Negative control: uninoculated discs.

With THT, KPC- and SPM-producing strains clearly showed overgrowth of the indicator strain towards the MEM disc at the intersection of the stria with the inhibition zone. In the IMP, NDM and VIM producing strains, deformation of the inhibition halo of the indicator strain could be observed at the intersection of the striations although the visualisation was not as clear (Figure 7).

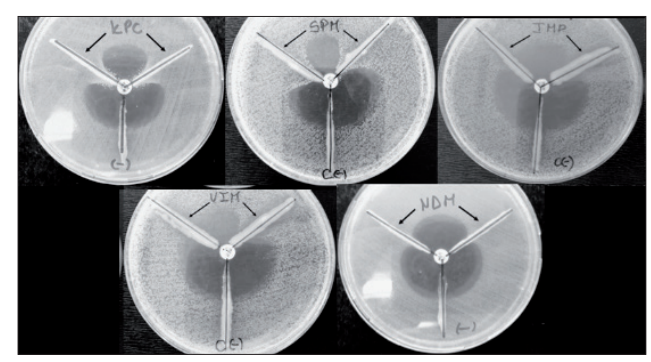

Figure 7: Triton Hodge Tests (THT). C (-)/ (-): Negative control: P. aeruginosa ATCC 27853

Table 2 shows the results obtained by comparing the techniques developed during the work. 
Table 2: Comparison of phenotypic techniques tested.

\begin{tabular}{|c|c|c|c|c|c|c|}
\hline \multirow{3}{*}{\multicolumn{2}{|c|}{$\begin{array}{l}\text { Techniques assessed } \\
\text { Difficulty in } \\
\text { getting it ready }\end{array}$}} & \multicolumn{5}{|c|}{ Comparisons according to: } \\
\hline & & \multirow{2}{*}{$\begin{array}{c}\text { Easeness } \\
\text { for the } \\
\text { interpretation } \\
\text { of results }\end{array}$} & \multirow{2}{*}{\begin{tabular}{c|} 
Ability to \\
distinguish \\
between MBL \\
and serine- \\
carbapenemase
\end{tabular}} & \multicolumn{2}{|c|}{$\begin{array}{l}\text { Time to get } \\
\text { results (h.) }\end{array}$} & \\
\hline & & & & Mín. & Máx. & \\
\hline \multirow{2}{*}{$\begin{array}{l}\text { Synergy } \\
\text { test with } \\
\text { EDTA and } \\
\text { BOR discs }\end{array}$} & & Medium * & Easy & Present & 18 & 24 \\
\hline & \multicolumn{5}{|c|}{$\begin{array}{l}\text { * } \text { Remark: The difficulty of the technique was given by } \\
\text { the distance between the inhibitor (EDTA or BOR) and the } \\
\text { antibiotic discs (IPM and MEM). The tests had to be repeated, } \\
\text { adjusting it, in order to observe the synergistic effect. }\end{array}$} & \\
\hline \multirow[t]{2}{*}{ CNPt-direct } & $\begin{array}{l}\text { With } \\
\text { Triton } \\
X-100\end{array}$ & Low & Easy & Absent & 0,33 & 2 \\
\hline & $\begin{array}{c}\text { Without } \\
\text { Triton } \\
\text { X-100 }\end{array}$ & Low & Easy & Absent & 1 & 2 \\
\hline \multirow[t]{2}{*}{$\begin{array}{c}\text { Carba-Blue } \\
\text { Method }\end{array}$} & & Medium * & Easy & Absent & 1 & 2 \\
\hline & \multicolumn{5}{|c|}{$\begin{array}{l}\text { * Remark: The technique was highly sensitive to } \\
\text { the pH of the prepared solutions. Optimum results } \\
\text { were obtained by filtering the solution. }\end{array}$} & \\
\hline \multirow[t]{2}{*}{ MIC } & & Low & Difficult * & Absent & 18 & 24 \\
\hline & \multicolumn{5}{|c|}{$\begin{array}{l}\text { * Remark: The IMP-producing strain presented a } 16 \mathrm{~mm} \\
\text { inhibition halo with colonies around the disc, considered } \\
\text { positive according to CLSI; however, in Van der Zwaluw et } \\
\text { al. (20) publication, they do not consider such a situation } \\
\text { and therefore it would correspond to a false negative. }\end{array}$} & \\
\hline \multicolumn{2}{|c|}{ mMIc y eMIC } & Low & Easy & Present & 18 & 24 \\
\hline DCT & & High* & Easy & Absent & 0,25 & 1 \\
\hline \multicolumn{6}{|c|}{$\begin{array}{l}{ }^{*} \text { Remark: Although the results obtained were optimal, } \\
\text { the technique was repeated in more than two occasions } \\
\text { due to the difficulty of completely drying the discs for } \\
\text { their preservation as they lost their colouring when they } \\
\text { dried and it was not possible to carry out the test. }\end{array}$} & \\
\hline \multicolumn{2}{|c|}{ THT } & Low & Easy & Absent & 18 & 24 \\
\hline
\end{tabular}

Low difficulty: no need for repetition; medium: had to be repeated twice; high: did not show satisfactory results in more than two attempts. Easy results: agreement between two or more observers; difficult: disagreement between two or more observers.

Min: minimum time for all carbapenemase-producing strains to test positive. Max. (maximum): time established by the author of the technique. MBL: metallo $\beta$-lactamases. MEM: meropenem. IPM: imipenem. EDTA: ethylenediamine triacetic acid. BOR: boronic acid. CNPtdirect: Carba NP direct. MIC: Carbapenem Inactivation Method. mMIC: Modified Carbapenem Inactivation Method. eMIC: Modified Carbapenem Inactivation Method + EDTA. DCT: Disk Carbapenemase Test. THT: Triton Hodge Test.

The DCT technique was the most difficult to set up, as it had to be repeated more than twice due to the difficulty in drying the discs. It was followed by the synergy test with EDTA and BOR discs and the Carba-Blue method. Both were repeated twice, achieving satisfactory results in the second instance. The CNPt-direct, MIC, mMIC-eMIC and THT methods did not present any difficulties in their set-up.
Regarding the interpretation of the results, most of the techniques did not present difficulties; however, the MIC technique presented failures with the IMP-producing strain. This difficulty was due to not knowing which criteria to use for interpretation as there is discordance between the criteria established by Van der Zwaluw et al. (20) and the CLSI (21).

As expected, the techniques with the ability to distinguish between MBL and serine-carbapenemases were the EDTA and BOR disc synergy assay and mMIC- eMIC.

The fastest technique to obtain results was DCT, with a minimum time of 15 minutes. This was followed by CNPt-direct and Carba-Blue with a minimum time of 20 minutes and $1 \mathrm{~h}$, respectively. The synergy, MIC, mMICeMIC and THT assays needed $18-24 \mathrm{~h}$ as they require plate development for reading. The research group's proposal to remove Triton X-100 from the CNPt-direct method was included in the analysis and we observed that the method took a minimum time of $1 \mathrm{~h}$. Otherwise, the results were exactly the same as the Triton X-100 method.

\section{Discussion}

Molecular techniques are considered the reference techniques for the detection of carbapenemase production (28). However, these methodologies are not easily applicable in daily clinical laboratory testing due to their high cost and complexity. Therefore, it is necessary to have laboratory methods that allow the search for these enzymes and that meet, as far as possible, conditions of simplicity, speed, reliability and accuracy

In the present work, different phenotypic techniques for the detection of carbapenemases have been analysed and compared with each other. In the EDTA disc synergy assay, all MBLs available for the work could be detected, making it a reliable method for the detection of MBLs. However, it presented the difficulty of depending on the distance between discs, making it necessary to repeat the technique until the appropriate distance was found. This situation was also described by authors such as Lee et al. (29) and Galloso et al. (30). We agree with Galloso et al. (30) that the synergy test requires technical expertise to discriminate between true synergism and the simple intersection of the inhibition halos of the drugs involved.

For the detection of the KPC strain, BOR was used, in which synergism could be observed in both MPI and MEM discs. The visualization was optimal and there was no problem when interpreting the results; however, the distances between the antibiotic discs and the inhibitor had to be adjusted. According to the literature (31), the method is highly sensitive and specific, but the technique and interpretations are undoubtedly subjective and operatordependent, and the distance between the discs needs to be adjusted according to the size of the carbapenem inhibition halo, a situation observed in our work. 
It has been reported that although there are other sensitive methods to detect the presence of $\beta$-lactamases, in particular carbapenemases in enterobacteria, these may give false positive results in isolates with decreased sensitivity to carbapenems due to a combination of BLEE plus impermeability (9).

The carbapenemase-ORB synergy method is a useful method for such cases given its high specificity for the detection of KPC-type carbapenemases (31), however, inhibition by ORB is not exclusive to KPC enzymes as it is also an efficient inhibitor of AmpC-type B-lactamases (Ambler class $\mathrm{C}$ and Bush and Jacoby group 1), which makes detection of KPCs difficult when this enzyme is present (32). In our work we agree with Nicola et al. (31), as the method proved to be suitable for the detection of the KPC-producing strain. In the comparative analysis of the techniques, the disc synergy method required more time to obtain results than the other techniques tested (CNPtdirect, Carba-Blue or DCT). This longer response time is the main drawback of these inhibitor synergy tests (28). However, it has the advantage of discriminating between MBL and serine-carbapenemases.

The CNPt-direct method and the Carba-Blue method proved to be the easiest to interpret due to the difference in colour between negative and positive results. Both methods also had the advantage of obtaining results quickly. However, they had the disadvantage of relying on the preparation of reagents that require small and precise weights, with the $\mathrm{pH}$ of the solutions being critical. We did not find substantial differences between both colourimetric methods analysed; however, in the work done by Pancotto et al. (33), they noted a better visualisation of the results with the Carba Blue method, due to the fact that it is easier to notice the colour changes from green to yellow than from red to orange/yellow.

The modification proposed by the research group to remove Triton X-100 from the methodology described by Pasteran et al. (18) produced excellent results. Only the minimum time to obtain positive results was affected, varying from 20 minutes to $1 \mathrm{~h}$ according to our proposal. We consider it an advantage of the research group's proposal to mention that the detergent Triton X-100 is not commonly used in clinical laboratories, so in laboratories where carbapenemase search assays are not commonly performed, it would increase the costs of the technique. A disadvantage to be taken into account of the described colorimetric methods is that they have a poor sensitivity for detecting carbapenemase-producing Acinetobacter spp. strains (13).

As for the MIC technique, the results were satisfactory for the KPC, SPM, NDM and VIM producing strains, while for the IMP producing strain the results were not as expected. It showed a halo of inhibition of the indicator strain after incubation for $24 \mathrm{~h}$, which is interpreted as a negative result according to the author of the methodology.
However, and according to the criteria established by CLSI (21), this halo would indicate a positive result (16 $\mathrm{mm}$ diameter with colonies around the disc).

This discordance caused problems when interpreting the results, that is the reason why we finally considered it as a false negative. Another aspect to consider is that, according to some research, the MIC method would have limitations in detecting carbapenemases that hydrolyse carbapenems inefficiently, e.g. OXA-type enzymes; MBL that require the addition of zinc to exert their catalytic activity or strains with low expression of carbapenemases (34).

When the mMIC method proposed by CLSI (21), which is similar to MIC but with some technical differences, was performed, all strains gave satisfactory results, an identical situation to the one observed by McMullen et al (35). The time required to obtain results for both methods was the same since they depend on the development of the indicator strain. As a result, there was no advantage of the MIC technique over the mMIC. Besides, while performing the Emic technique jointly, it was possible to detect all the MBL used in the development of the work.

MIC and mMIC-eMIC techniques use antibiotic susceptibility test discs, which are common in low/medium complexity laboratories. They are available at low cost and have a long lifetime, greatly improving practicality and reducing costs and labour. However, they require more time to obtain results, a situation described by other authors $(34,36)$. Tamma et al. (37) have warned about the possibility of false negatives if the isolate under study co-produces serine and metallo $\beta$-lactamases, especially when the co-production is due to OXA and NDM enzymes.

On the other hand, these methods are not recommended for the detection of carbapenemases in Acinetobacter strains. As for the DCT technique, the results were satisfactory, but disc preparation was tedious and difficult to achieve. The discs, upon drying, were highly sensitive to environmental conditions, varying in colour and making subsequent interpretation difficult.

In comparison with the CNPt-direct and Carba-Blue techniques, we found no improvement in the simplification of the method; even though the results are obtained in minutes, the distrust in the discs, due to the difficulty in their drying, led to doubts about the results even when the positive and negative controls gave correct results. According to the authors of the methodology (22), the prepared dry discs are stable at $-20^{\circ} \mathrm{C}$ and $4^{\circ} \mathrm{C}$, a situation that is not easy to achieve as it requires equipment that is not usual in a low/medium complexity laboratory (incubator with mechanical air circulation).

THT is an improved approach to MHT, as the latter shows low sensitivity for detecting NDM-type metallo ß-lactamases. This limitation is overcome by the use of Triton X-100, which releases the lipoprotein that is anchored to the membrane, thus allowing its detection. 
In our work, the KPC, SPM and NDM strains showed excellent results. However, the IMP and VIM strains did not show such clear results, so the interpretation may be subjective with respect to the observer, a problem shared by other authors $(38,39)$.

\section{Conclussions}

This study evaluated and compared phenotypic methods capable of detecting KPC, VIM, IMP, NDM and SPM carbapenemases that are simple, rapid and inexpensive, and proposed modifications to one of the existing techniques. All methods tested detect the presence of carbapenemase enzymes, and therefore the choice of methods will depend on the interests and resources of each laboratory. The mMIC-eMIC method is simple, easy to interpret and capable of detecting MBL enzymes but it has the disadvantage of obtaining results in 18-24 h. The CNPtdirect and Carba-Blue techniques are inexpensive and fast but depend on reagent preparation and $\mathrm{pH}$ adjustment of the solutions. The synergy method with EDTA and BOR discs, and the THT method are methods that can be applied for the detection of carbapenemases; however, the interpretation of the results can be subjective and requires technical expertise to discriminate between true synergism and the simple intersection of the inhibition halos of the drugs involved. As for DCT, it is not a method that we can recommend in our experience (difficulty in preparing the discs); nevertheless, the proposal to obtain results in minutes makes it a tempting technique to apply if the conditions established by the authors of the method are met.

\section{Acknowledgements}

During the development of the work, Florencia Angelini awarded a Scholarship for the Stimulation of Scientific Vocations from the National Interuniversity Council (EVC-CIN).

To the Laboratory of Bacterial Resistance, Faculty of Pharmacy and Biochemistry, University of Buenos Aires for the provision of the carbapenemase-producing strains.

\section{References}

1. Bonomo RA, Burd EM, Conly J, Limbago BM, Poirel L, Segre JA, Westblade LF. Carbapenemase-producing organisms: A global scourge, Clin Infect Dis. 2018; 66(8):12901297.

2. Reyes JA, Melano R, Cárdenas PA, Trueba G. Mobile genetic elements associated with carbapenemase genes in South American Enterobacterales. Braz J Infect Dis. 2020; 24(3):231-238.

3. Bush K. Past and present perspectives on $\beta$-Lactamases. Antimicrob Agents Chemother. 2018; 62(10):e01076-18.
4. Aguilera-Alonso D, Escosa-García L, Saavedra-Lozano J, Cercenado E, Baquero-Artigao F. Carbapenem-resistant Gramnegative bacterial infections in children Antimicrob Agents Chemother. 2020; 64(3):e02183-19.

5. Zhang Y, Chen XL, Huang AW, Liu SL, Liu WJ, Zhang N, Lu XZ. Mortality attributable to carbapenem-resistant Pseudomonas aeruginosa bacteremia: a meta-analysis of cohort studies. Emerg Microbes Infect. 2016; 5(3): e27.

6. Tamma PD, Goodman KE, Harris AD, Tekle T, Roberts A, Taiwo A, Simner PJ. Comparing the outcomes of patients with carbapenemase-producing and non-carbapenemaseproducing carbapenem-resistant Enterobacteriaceae bacteremia. Clin Infect Dis.2017; 64(3):257-264.

7. Ambler RP. A standard numbering scheme for the class $A$ $\beta$-lactamases. Biochem J.1991; 276:269-272.

8. Bush K, Jacoby GA. Updated functional classification of beta-lactamases. Antimicrob Agents Chemother. 2010; 54:969-76

9. Elshamy AA, Aboshanab KM. A review on bacterial resistance to carbapenems: epidemiology, detection and treatment options. Future Sci OA. 2020; 6(3):FSO438.

10. Porreca AM, Sullivan KV, Gallagher Jc. The epidemiology, evolution, and treatment of KPC-producing organisms. Curr Infect Dis Rep.2018; 20(6):13.

11. Swathi $\mathbf{C H}$, Chikala R,Ratnakar KS, Sritharan v. A structural, epidemiological \& genetic overview of Klebsiella pneumoniae carbapenemases (KPCs). Indian J Med Res. 2016; 144(1): 21-31.

12. Bakthavatchalam YD, Anandan $\mathrm{S}$, veeraraghavan B. Laboratory detection and clinical implication of Oxacillinase-48 like carbapenemase: the hidden threat. J Glob Infect Dis. 2016; 8(1):41-50.

13. Tamma PD, Simner PJ. Phenotypic detection of carbapenemase-producing organisms from clinical isolates. $\mathrm{J}$ Clin Microbiol. 2018; 56(11):e01140-18.

14. Meletis G. Carbapenem resistance: overview of the problem and future perspectives. Ther Adv Infect Dis. 2016; 3(1):15-21.

15. Nordmann P, Poirel L. Epidemiology and diagnostics of carbapenem resistance in Gram-negative bacteria. Clin Infect Dis. 2019; 69(Supp1 7):S521-S528.

16. Radice $M$, Marín $M$, Giovanakis $M$, Vay C , Almuzara M , Limansky A, Casellas JM , Famiglietti A , Quinteros M, Bantar C, Galas M , Kovensky Pupko J , Nicola F , Pasterán F, Soloaga R , Gutkind G. Criterios de ensayo, interpretación e informe de las pruebas de sensibilidad a los antibióticos en los bacilos gram negativos no fermentadores de importancia clínica: recomendaciones de la Subcomisión de Antimicrobianos de la Sociedad Argentina de Bacteriología, Micología y Parasitología Clínicas, Asociación Argentina de Microbiología. Rev Argent Microbiol. 2011; 43: 136-153.

17. Nordmann P, Poirel L, Dortet L. Rapid detection of carbapenemase-producing Enterobacteriaceae. Emerg Infect Dis. 2012, 18:1503-1507. 
18. Pasteran F, Tijet N, Melano RG, Corso A. Simplified protocol for Carba NP test for enhanced detection of carbapenemase producers directly from bacterial cultures. J Clin Microbiol. 2015; 53(12):3908-3911.

19. Pasteran F, Veliz $\mathrm{O}$, Ceriana $\mathrm{P}$, Lucero $\mathrm{C}$, Rapoport $\mathrm{M}$, Albornoz $\mathrm{E}$, Gomez S, Corso A; ReLAVRA Network Group. Evaluation of the Blue-Carba test for rapid detection of carbapenemases in gram-negative bacilli. J Clin Microbiol. 2015; 53(6): 1996-1998.

20. van der Zwaluw K, de Haan A, Pluister GN, Bootsma HJ, de Neeling AJ, Schouls LM. The Carbapenem inactivation method (CIM), a simple and low-cost alternative for the Carba NP test to assess phenotypic carbapenemase activity in gramnegative rods. PLoS ONE. 2015; 10(3):e0123690.

21. Clinical and Laboratory Standards Institute. Performance standards for antimicrobial susceptibility testing: Twenty-eighth informational supplement M100-S 28. 2018. CLSI, Wayne, PA, USA.

22. Kim H, Sung JY, Yong D, Jeong SH, Song W, Lee K, Chong Y. Disk carbapenemase test for the rapid detection of KPC-, $N D M$-, and other metallo- $\beta$-lactamase-producing gramnegative bacilli. Ann Lab Med. 2016; 36(5):434-440.

23. Pasteran F, Gonzalez L, Albornoz E, Bahr G, Vila AJ, Corso A. Triton Hodge Test: Improved protocol for modified Hodge test for enhanced detection of NDM and other carbapenemase producers. J Clin Microbiol. 2016; 54(3):640649.

24. Clinical and Laboratory Standards Institute. Performance standards for antimicrobial susceptibility testing: twenty-fifth informational supplement M100-S26. 2016. CLSI, Wayne, PA, USA.

25. Prat Miranda S. Recomendaciones para detección carbapenemasas en enterobacterias y Pseudomonas aeruginosa. 2018. Disponible en: http://www.ispch. $\mathrm{cl} /$ sites/default/files/Recomendaciones $\% 20$ para $\% 20$ detecci $\%$ C3\%B3n $\% 20$ carbapenemasas $\% 20$ en $\% 20$ enterobacterias $\% 20 \mathrm{y} \% 20$ pseudomonas $\% 20$ aeruginosa..pdf.

26. Subcomisión de antimicrobianos (SADEBAC-AAM). Caracterización fenotípica de la resistencia a los $\beta$-lactamicos en Pseudomonas aeruginosa y Acinetobacter spp. Disponible en: https://www.aam.org.ar/src/img_ up/21072014.1.pdf.

27. National Committee for Clinical Laboratory Standards. Performance standards for antimicrobial disk. Approved Standard; M2-A7. 2000. NCCLS, Wayne, Pa, USA.

28. Osei Sekyere J, Govinden U, Essack SY. Review of established and innovative detection methods for carbapenemaseproducing Gram-negative bacteria. J Appl Microbiol, 2015; 119: 1219-1233.

29. Lee K, Chong Y, Shin HB, Kim YA, Yong D, Yum JH. Modified Hodge and EDTA-disk synergy tests to screen metallo$\beta$-lactamase-producing strains of Pseudomonas and Acinetobacter species. Clin Microbiol Infect. 2001; 7(2):88-91.
30. Galloso P, Lezcano MT, Quiroga M. Evaluación de métodos fenotípicos para la detección de cepas de Pseudomonas aeruginosa productoras de metalo- $\beta$-lactamasas. Rev Cienc Tecnol. 2010; 14:8-13.

31. Nicola FG, Nievas J, Smayevsky J. Evaluación de diversos métodos fenotípicos para la detección de carbapenemasas KPC en Klebsiella pneumoniae. Rev Argent Microbiol. 2012; 44(4):290-302.

32. Navarro F, Calvo J, Cantón R., Fernández-Cuenca F, Mirelis B. Detección fenotípica de mecanismos de resistencia en microorganismos gramnegativos. Enferm Infecc Microbiol Clin. 2011; 29(7):524-534.

33. Pancotto LR, Nodari CS, Rozales FP, Soldi T, Siqueira CG, Freitas AL, Barth AL. Performance of rapid tests for carbapenemase detection among Brazilian Enterobacteriaceae isolates. Braz J Microbiol. 2018; 49(4):914-918.

34. Pierce VM, Simner PJ, Lonsway DR, Roe-Carpenter DE, Johnson JK, Brasso WB, Bobenchik AM, Lockett ZC, Charnot-Katsikas A, Ferraro MJ, Thomson RB, Jr, Jenkins SG, Limbago BM, Das S. Modified carbapenem inactivation method for phenotypic detection of carbapenemase production among Enterobacteriaceae. J Clin Microbiol. 2017; 55:2321-2333.

35. McMullen AR, Yarbrough ML, Wallace MA, Shupe A, Burnham CD. Evaluation of genotypic and phenotypic methods to detect carbapenemase production in Gram-negative bacilli. Clin Chem. 2017; 63(3):723-730.

36. Zhong H, Wu ML, Feng WJ, Huang SF, Yang P. Accuracy and applicability of different phenotypic methods for carbapenemase detection in Enterobacteriaceae: A systematic review and meta-analysis. J Glob Antimicrob Resist. 2020; 21:138-147.

37. Tamma PD, Opene BN, Gluck A, Chambers KK, Carroll KC, Simner PJ. Comparison of 11 phenotypic assays for accurate detection of carbapenemase-producing Enterobacteriaceae. J Clin Microbiol 2017; 55:1046-1055.

38. Sun K, Xu X, Yan J, Zhang L. (2017). Evaluation of six phenotypic methods for the detection of carbapenemases in Gram-negative bacteria with characterized resistance mechanisms. Ann Lab Med. 2017; 37(4):305-312.

39. Esther J, Edwin D, Uma. Prevalence of carbapenem resistant non-fermenting Gram negative bacterial infection and identification of carbapenemase producing NFGNB isolates by simple phenotypic tests. J Clin Diagn Res. 2017; 11(3):10-13. 